\title{
A Revolução por outro olhar
}

\author{
Márcia Pileggi Vinha
}

\begin{abstract}
Resumo: Tradução do russo para o português de trecho do diário de Ivan Búnin, Dias Malditos. Após introdução sobre o autor e sua obra, o artigo discute o processo de tomada de decisão por parte do tradutor, descrevendo questões como a opșão pelo emprego de notas de rodapé e contaminação do texto na lingua de chegada.
\end{abstract}

Palavras-chave: tradução comentada; diário; Revolução Russa; Ivan Búnin

O livro Dias Malditos, de Ivan Búnin (1870-1953), consiste no diário do escritor referente aos anos de 1918 e 1919, período que marca seus últimos dias na Rússia, anteriores ao exílio. A obra foi publicada em 1936, quase duas décadas depois de escrita, vindo a ser realmente celebrada pela opinião pública russa nos anos noventa quando, com o fim da censura soviética ela pôde circular livremente entre os leitores. Considerada importante obra da literatura testemunhal, recentemente aceita-se também sua interpretação como obra ficcional, tendo como justificativa, principalmente, o intenso trabalho editorial de Búnin com vistas a tocar o leitor. Sabe-se que, à diferença de outros escritores, escrever e reescrever o mesmo texto era prática central no seu trabalho criativo.

Assim foi com seus poemas e célebres obras, como a novela A Aldeia (1910) e o conto O Senhor de São Francisco (1915), criados ainda na Rússia imperial. Em 1921, Búnin emigrou para a França, deixando para trás a guerra civil em que os brancos perdiam cada vez mais força. Ele nunca mais retornaria, embora tenha cogitado fazê-lo num momento posterior de seu exílio. Enquanto emigrante, a Rússia continuou sendo o cenário principal de suas criações, fase marcada pelo êxito de receber o Prêmio Nobel de Literatura em 1933, tendo sido Búnin o primeiro escritor russo a consegui-lo. No exílio ele escreveria obras que seriam ainda mais celebradas, como A Vida de Arseniev (1933) e Aléias Escuras (1943), que se tornaram parte dos cânones literários russos. 
Dias Malditos é composto por notas curtas e rotineiras, datadas, que descrevem as tragédias da Guerra Civil mescladas a afazeres triviais num ambiente de profunda mudança social e política. Em suas anotações o escritor revela também o próprio olhar sobre como a sociedade passou a absorver as modificações em curso. Os relatos são permeados pelas opiniões do autor, contrárias ao regime bolchevista que acabara de aniquilar o tsarismo e, no momento da narrativa, procedia com a aniquilação de toda uma classe social - a burguesia, representada por nobres, burgueses e um incontável número de artistas e intelectuais - processo que Búnin vivia, testemunhava e temia. O narrador também reproduz ao leitor as opiniões de pessoas da rua, de amigos, bem como excertos de jornais bolchevistas, retratando assim a diversidade de olhares sobre o momento histórico e compondo um verdadeiro debate entre os dois lados de uma sociedade dividida entre os apoiadores do antigo regime e os defensores do novo. Desta forma, o leitor pode acompanhar a experiência subjetiva de testemunhas, tendo acesso à atmosfera da época, na qual a polarização da sociedade já era tão intensa, que qualquer posicionamento crítico sobre os acontecimentos não passaria livre da categorização de direita ou esquerda. A voz de um branco prevalece, por certo, questionando a legitimidade e a violência do poder tomado e exercido pelos vermelhos.

\section{2 апреля.}

Вспомнился мерзкий Аень с Аождем, снегом, грязью, - Москва, прошлый год, конец марта. Через Кудринскую площадь тянутся бедные похороны - и вАруг, бешено стреляя мотоцикцетом, вылетает с Никитской животное в кожаном картузе и кожаной куртке, на Аету грозит, машет огромным револьвером и обдает грязью несущих гроб:

- Аолой с Аороги!

Несущие шарахаются в сторону и, спотыкаясь, тряся гроб, бегут со всех ног. А на углу стоит старуха и, согнувшись, плачет так горько, что я невольно приостанавливаюсь и начинаю утешать, успокаивать. Я бормочу: - «Ну будет, будет, Бог с тобой!» - спрашиваю: - «Родня, верно, покойник-то?» А старуха хочет передохнуть, одолеть слезы и наконец с трудом выговаривает:

- Нет... Чужой... Завидую...

И еще вспомнилось. Москва, конец марта позапрошлого года. Большой, толстый князь Трубецкой кричит, театрально сжимая свои маленькие кулачки: 
- Помните, господа: пгусский сапог безжалостно газдавит нежные гостки гусской свободы! Все на защиту ее!

Устами князя говорили тогда сотни тысяч уст. Нечего сказать, нашли Аля кого защищать «русскую свободу!»

Зимой 18 года те же сотни тысяч возАожили все свои упования на спасение (только уже не русской свободы) именно через немцев. Вся Москва бредила их приходом.

Понедельник, газет нет, отдых в моем помешательстве (Алящемся с самого начала войны) на чтении их. Зачем я наА собою зверствую, рву себе сердце этим чтением?

На редкость твердо уверены все эти Пешехоновы, что только им принадлежит решение российской судьбы. И когда же? КогАа они АОАжны были бы в тартарары провалиться хотя бы от одного стыда за все то, что они явили на Аиво всему миру за свое шестимесячное царствование в 17 году.

Совершенно нестерпим большевистский жаргон. А каков был вообще язык наших Аевых? «С цинизмом, доходящим до грации... Нынче брюнет, завтра блондин... Чтение в сердцах... Учинить допрос с пристрастием... ИАи - или: третьего не Аано... САелать надлежащие выводы... Кому сие ведать надлежит... Вариться в собственном соку... Аовкость рук... Нововременские молодцы...» А это употребление с какой-то якобы ядовитейшей иронией (неизвестно наА чем и наА кем) высокого стиля? Ведь Ааже у Короленко (особенно в письмах) это на каждом шагу. Непременно не цошадь, а Россинант, вместо «я сел писать» - «я оседлал своего Пегаса», жандармы - «мундиры небесного цвета».

\section{2 de abril.}

Eu me lembrei de um dia horrível, com chuva, neve e lama - ano passado, Moscou, final de março. Pela Praça Kudrinskaya se arrastava um pobre cortejo fúnebre até que, de repente, atirando insano com uma motocicleta, vem voando da Nikitskaya um animal de quepe de couro e casaco de couro que, apontando um revólver enorme, ameaça e espirra lama nas pessoas que carregavam o caixão:

- Fora do caminho!

De um salto eles se afastam para o lado, e tropeçando, chacoalhando o caixão, correm o mais rápido que podem. E, num canto, uma velha, contorcendo-se, 
chora de um jeito tão amargo que eu involuntariamente paro e começo a consolá-la, a acalmá-la. Balbucio: “Calma, calma... Deus está com você!" e pergunto: "É seu parente, o falecido, não é?” A velha, que quer respirar e limpar as lágrimas, finalmente articula:

- Não... não é... Que inveja, a minha...

Mais lembranças. Moscou, final de março do ano retrasado. O príncipe Trubetskoi ${ }^{1}$, gordo, grande, está gritando, seus punhos pequeninos cerrados de forma teatral.

- Lembguem-se, senhogues! A bota pgussa vai pisar sem dó nesses delicados bgotos da libegdade russa! Todos pela sua pgoteção!

Centenas de milhares de lábios repetiram suas palavras. Sem nada mais a dizer - já encontraram alguém para defender a "liberdade russa".

No inverno de dezoito essas mesmas centenas de milhares colocaram suas esperanças na salvação (que já não era mais a liberdade russa), em particular, pelos alemães. Moscou inteira delirou com sua chegada.

Hoje é segunda, jornal não circula, e eu descanso da minha insanidade (que dura desde o comecinho da guerra) por lê-los. Por que eu cometo essa atrocidade contra mim mesmo, despedaçando meu coração a cada leitura?

Todos esses Pechekhonoves ${ }^{3}$ estão convencidos de um jeito tão certo e excepcional, que só a eles cabe sugerir uma solução para o destino russo. Mas quando mesmo? Quando eles deveriam ter ido parar no quinto dos infernos pela vergonha de tudo o que mostraram ao mundo inteiro com aquela maravilha de reinado de um total de seis meses no ano de dezessete.

O jargão bolchevique é absolutamente insuportável. E qual foi a língua da nossa esquerda? "Com cinismo, chegando ao gracioso... Atualmente morena, amanhã loira... A leitura de todo coração... Fazer um interrogatório com afeição... Ou, ou: outra opção não precisa... Chegar a uma conclusão devida... A quem, presentemente, é conhecido ser devido... Cozinhar no seu próprio suco... A destreza das mãos... Os heróis da nova era...” E esse emprego com uma certa ironia, supostamente maliciosa (sem ficar claro contra o que e contra quem), em

1 No excerto, Búnin caracteriza o personagem como uma pessoa com anciloglossia.

2 Aleksei Pechekhónov (1967-1933), político socialista, líder partidário e economista, foi ministro do Governo Provisório por alguns meses. Búnin se dirige a seus partidários.

3 Excerto traduzido do inglês. Para uma discussão detalhada dos fatos verdadeiros e falsos, veja Marullo, 1998, p. 43, 53, 55, 57, 94, 83, 124, 137, 175, 146, 179, 186 e 203. 
estilo elevado? E não é que até Korolenko (especialmente em cartas) tem isso a cada passo? É infalível: não é cavalo, é Roucinante; ao invés de "eu me sentei para escrever", é "eu selei meu Pégasus"; não é farda, é "uniformes de cor celestial".

Ao leitor brasileiro contemporâneo que acompanha o cenário político nacional enquanto lê Dias Malditos, é inevitável relacionar as mudanças pelas quais a Rússia atravessava às mudanças pelas quais o Brasil atravessou nos últimos anos e ainda atravessa. As analogias são tantas que o tradutor brasileiro projeta características de sua própria sociedade no texto de tal forma que o vivencia como se a história não lhe fosse de todo desconhecida, apesar de algumas semelhanças serem um tanto às avessas, como será esclarecido. Tamanha proximidade nos pareceu um desafio quase orgânico, talvez maior do que as dificuldades impostas pelas questões técnicas da tradução.

Não obstante os cenários distintos que separam o leitor de hoje dos personagens da época, a polarização entre direita e esquerda é um dos traços que guardamos em comum. O crítico Simon Karlinsky (1977, p. 5-6), exilado como Búnin, comenta que, à época, nenhum posicionamento sobre os acontecimentos em questão poderia suplantar essa categorização binária, que acabava reduzindo a rótulos simplistas críticas com poder de esclarecimento, dificultando assim o diálogo. Como exemplo ele cita a "Western self-censorship", ou seja, a política de alguns veículos dos países europeus e dos EUA de não publicar escritores de direita, basicamente a esmagadora maioria dos emigrados. Tal categorização ignorava, por exemplo, que os exilados não apenas emigravam pelo princípio da liberdade na arte, mas também para preservar a própria vida - eram refugiados. Que os rótulos caminham em direção contrária ao esclarecimento já se sabe. E o que o livro nos faz refletir é sobre qual eficácia há, no debate nacional sobre os rumos de nossa nação, de nos chamarmos mutuamente de petralhas, coxinhas, patos, mortadelas, CBFs e paneleiros.

Outro paralelo inevitável é o visível aumento da agressividade quando o asunto é política, tanto entre estranhos como entre pessoas ligadas por um relacionamento amistoso. Testemunhamos no Brasil a cólera com que opiniões diferentes se encontravam pessoal e virtualmente, cólera que também existia nas ruas de Odessa e Moscou. Em particular, Búnin também narra as trocas de acusações e atribuição mútua de responsabilidade entre esses dois pólos da sociedade: se na Rússia a esquerda acusava a elite de negligenciar e abusar dos trabalhadores, a direita os acusava de uma longa lista de extorsão, roubo, assassinatos e linchamentos, violência que por princípio aniquilaria o próprio ideal revolucionário, argumentavam. 
Hoje, no nosso cenário, vemos muitos representantes da direita responsabilizando representantes da esquerda pelas consequências nefastas de um impeachment que eles apoiaram, enquanto a esquerda chama a direita à responsabilidade, pois sem tal apoio o governo não teria mudado. A própria interpretação de como se deu a mudança do poder político também permite um paralelo às avessas com a Revolução: grosso modo, se a tomada do poder pelos bolcheviques foi uma vitória legítima para a esquerda, para a direita era foi violenta, despreparada e ilegítima; já aqui, observamos uma direita que vê o impeachment como uma conquista advinda de instrumentos legais que refletem um avanço da democracia brasileira e maior conscientização popular, ao mesmo tempo em que se vê uma esquerda apontando para a incoerência factual e legal de um impeachment que considera ser um golpe brando. Dias Malditos não deixa dúvida de que, tanto os russos de ontem como os brasileiros de hoje ressentem as mudanças que vivenciam e remoem a sensação de terem sido injustiçados pelo outro lado que levou cabo tais alterações, sensação que no cenário brasileiro parece ainda estar acesa e mediar nossas relações e a forma como atuamos na sociedade. A ideia de injustiça parece estar na base das reações acaloradas em ambos os cenários, promovendo as acusações e reivindicações de reparo, inevitavelmente legítimas a ambos os lados.

Outra analogia pertinente diz respeito às notícias falsas e boatos, que abundavam tanto no período em que elas levavam dias para chegar ao leitor, como nos dias atuais, em que elas demoram segundos para correr o planeta. Em diversas passagens Búnin narra as expectativas causadas por uma notícia que se verifica, posteriormente, infundada. Muitas delas são apresentadas ao leitor por conversas triviais, caracterizando a atmosfera de espera ansiosa e grande incerteza, como no trecho abaixo:

7 de março.

$\mathrm{Na}$ cidade estão falando:

- Eles resolveram exterminar, no geral, todos, todos menores de sete anos para que depois nem uma pessoa se lembre de nossa época.

Pergunto ao zelador:

- O que você acha, é verdade?

Ele dá um suspiro: - Tudo é possível, tudo é possível.

- Será possível que o povo vai deixar?

- Vai, meu caro bárin, e como vai! Fazer o quê com eles? Dizem que foram duzentos anos de domínio dos tártaros, mas será que naquela época o povo já era assim tão mole? (Bunin, 2009, p. 341) 
Thomas Marullo, tradutor da obra para o inglês e estudioso do escritor, deu-se ao trabalho meticuloso de verificar cada notícia que Búnin compartilhava no diário. Vale reproduzir um trecho em que Búnin toma nota: "Aniuta disse: $\mathrm{O}$ Exército Vermelho foi perseguido em Moscou.". Marullo esclarece o comentário em nota de rodapé: "Nada poderia estar mais longe da verdade." (1998, p. 124)4. Isso nos faz lembrar os vídeos e textos que circulam virtualmente com informações tomadas como verdade por muitos, porém sem fundamento legítimo, que mais disseminam o preconceito do que esclarecem. Como sabemos, nem sempre as notícias são verificadas antes de serem tomadas como verdades. Esses paralelos acabam levando o tradutor a um envolvimento emocional com o texto, que não necessariamente contribui para uma tradução leal, como exemplificaremos em breve.

Deixando de lado as questões subjetivas e voltando o olhar para os componentes formais do texto, a composição é constituída por uma aparente "displicência estilística", certamente proposital, entremeada por trechos de linguagem literária, suspendendo por vezes o ritmo da obra como um todo. $\mathrm{O}$ tom de discurso oral, no entanto, prevalece. Nesse excerto a linguagem oral se mistura visivelmente à literária. Tal efeito é obtido pela ausência de preposições e de conectivos em associação à figuras de linguagem, característica de um texto trabalhado: a marcação temporária, por exemplo, não ocorre no genitivo, nem a espacial, no prepositivo, como manda a regra, sendo traços característicos da fala e até da linguagem cinematográfica. Metáforas, como "atirando insano com uma motocicleta" complementam, por exemplo, a repetição "de couro" e a palavra "animal" como xingamento, que remetem à informalidade. Confessamos o desejo de se inserir pequenos vocábulos que tornariam o texto em português mais fluído, como "Eu me lembrei de um dia horrível (...) era em Moscou no ano passado, no final de março", pois eles não prejudicariam o sentido do texto. Igualmente, houve o ensejo de se ocultar a repetição "de couro", pois soaria mais palatável aos ouvidos brasileiros. Contudo, evitando causar desequilibrio ao contraste de tons, optamos por mantê-los no português.

A palavra чужой (tchujór), nesse caso, "que não é da família”, foi substituída apenas pela dupla negação, tão característica ao português coloquial, e cuja compreensão é dada somente a partir da pergunta do interlocutor. Завилую (zavíduiu), se traduzido na primeira pessoa no Presente do Indicativo, conforme no original,

4 Excerto traduzido do inglês. Para uma discussão detalhada dos fatos verdadeiros e falsos, veja Marullo, 1998, p. 43, 53, 55, 57, 94, 83, 124, 137, 175, 146, 179, 186 e 203. 
comprometeria o tom de conversa e aproximaria o texto do tom literário, já que no português do Brasil utilizamos esse tempo na fala para ações genéricas e habituais (Garcia, 1991, p. 91). Cogitamos a possibilidade de traduzi-lo por "estou com inveja...", que nos pareceu demasiado neutro, ou então por "estou é com inveja", mas este já soaria enfático demais, de forma que chegamos ao "que inveja, a minha...", frase que condensa tanto a frustração e o desejo, recuperando a mesma ideia do original, sem perder em força expressiva. Combinada à dupla negação, ambas garantiriam a oralidade que marca esse diálogo entre dois desconhecidos, nesse trecho representada em particular pelos coloquiais покойник-то (pokóinik-to) е верно (viérno).

O texto também faz alusão aos acontecimentos da época, período de Guerra Civil e constantes lutas, conquistas e perdas de territórios nem sempre familiares ao leitor russo. São recorrentes menções a pormenores que somente historiadores especialistas, talvez, possam responder. Personalidades da época, nem sempre conhecidas do leitor da língua de origem e de uma outra época, são igualmente citados. Nesse excerto menciona-se o Príncipe Trubetskoi. A indesejada nota de rodapé surgiu como solução para esse artigo, entretanto, no caso da publicação da obra completa, um índice onomástico também seria uma saída mais aceitável para driblar as notas excessivas, que devem ser salvaguardadas para explicações históricas e para elucidar questões de tradução, no caso, como a representação do defeito de fala. Boris Schnaiderman comenta que as notas revelam, "além do tempo de enunciação e do tempo do enunciado, o tempo da tradução" (2011, p. 60), com o que devemos concordar. Contudo, seguindo o modelo do respeitado tradutor, respondemos a essa afirmação com a pergunta que ele mesmo formula: seriam as notas sempre uma calamidade? Nesse caso, Búnin faz uma descrição jocosa, como se a personagem em questão tivesse a língua presa. E como traduzir isso? Optamos pelo ato desmedido de tentar reproduzir o efeito tal como ele é representado, fonetica e derrogatoriamente, no português e combiná-lo com uma nota, colocando as intenções do autor. Assumimos o risco de cometer um excesso na própria tradução, porém por outro lado ganhamos ao nos aproximarmos de como o brasileiro, num ambiente informal, reproduz o fenômeno de forma depreciativa, tal como Búnin. Tendo em mente que nosso ofício é um caminho cheio de armadilhas, ficamos novamente com o conselho do experiente tradutor, ao compartilhar conosco que "a lição dos tropeços talvez seja tão importante como a dos êxitos" (2011, p. 15), acreditando que no futuro talvez encontremos uma solução melhor a esse problema.

Ao representar a linguagem dos veículos de comunicação da época, já submetidos à censura soviética, Búnin lista pleonasmos e expressões incoerentes, 
dando a entender que elas almejam o elevado e pecam pelo excesso, tornando-se ridículas. Ele as atribuiu aos наших мевых (nachikh levikh), literalmente, "nossos esquerdistas". A tradução literal dessa expressão nos pareceu inicialmente ideal: tanto Búnin era considerado um "direitista" como os comunistas, "esquerdistas". Ao tradutor, a lógica era de que no Brasil, as pessoas de posicionamento político de esquerda são consideradas "esquerdistas" pelas pessoas de direita, tal como o narrador faz; logo, a tradução literal parecia não ter objeções. Entretanto, essa solução imediata convivia com um desconforto difuso, que nos remete diretamente à discussão a respeito dos possíveis paralelos entre os cenários do Brasil de hoje e da Rússia de então para esclarecê-lo. A provocação de Búnin sobre o atendado ao "bom russo" possui análogo no cenário político brasileiro e, em particular, no que se refere ao atentado ao "bom português". Para nos convencermos disso, basta recordar as chacotas sobre o modo de falar do presidente Lula, as discussões sobre presidenta ou presidente e as comemorações, após impeachment, de que finalmente o Brasil teria um presidente que soubesse falar português, em parte porque o presidente atual também é conhecido por utilizar mesóclises, como manda o "bom português", apesar da prática questionável. As reflexões invocaram inevitáveis reflexões e posicionamento sobre os valores da sociedade brasileira por parte do tradutor. A semelhança dos cenários e a fusão do próprio tradutor-leitor com as discussões misturadas - política, gramática e sociolinguística - pareciam agravar a sensação de desconforto, sem levar à decisão clara sobre qual termo utilizar para a esquerda. Seria o correspondente "esquerditas" uma opção que prezaria pelas normas da língua, que o tradutor deveria necessariamente preservar tendo como referência o texto original? No século passado Búnin estava defendendo o "bom russo" ao empregar as palavras наших мевых (nachikh levikh) - o que nos faz perguntar se a escolha eleita estaria fazendo o mesmo no português contemporâneo. Foi então que Seligmann (2005, p. 190), pareceu orientar a resolução desse conflito, com a afirmação: "É apenas abandonando uma coisa que a nomeamos" (apud Benjamin, 1972, p. 506), ou seja, o distanciamento implica numa visão crítica, que perde de vista o self, os vocábulos e seu contexto, para depois se reaproximar deles. Em outras palavras, "a reflexão implica na saída do indivíduo de si mesmo, que se dá através do confronto com um 'outro”' (Seligmann, p. 190). Com tal auxílio, compreendemos que embora formalmente equivalentes, a opção pela tradução literal seria um equívoco semântico, já que a forma no português, além de ser um neologismo recente, reproduz uma imagem social negativa do falante, incompatível com o russo, no qual evidencia-se mais um sarcasmo. "Esquerdista", portanto, resultaria numa contaminação advinda de um tradutor excessivamente enredado num texto com o qual se identifica. O termo mais induziria, do que traduziria. 
Assim, a opção do bom e velho "de esquerda" nos pareceu a mais correta, pois contribuiria para uma leitura mais asséptica do texto.

\section{Referências}

GARCIA, Othon M. Comunicação em Prosa Moderna. Rio de Janeiro: Editora FGV, 2010.

BUNIN, Ivan. Jižn Arseneva. Okaiannie dni. Moscou: AST, 2009.

KARLINSKY, Simon. The bitter air of exile: Russian writers in the west, 1922-1972. [s.n.]: University of California Press, 1977.

MARULLO, Tomas. Cursed Days. A diary of Revolution. Chicago: Ivan R. Dee, 1998.

SCHNAIDERMAN, Boris. Tradução, ato desmedido. São Paulo: Perspectiva, 2011.

SELIGMANN, Márcio. "Haroldo de Campos: tradução como formação e 'abandono' da identidade” (pp. 189-204). In: O local da diferença. São Paulo, Editora 34: 2005. 